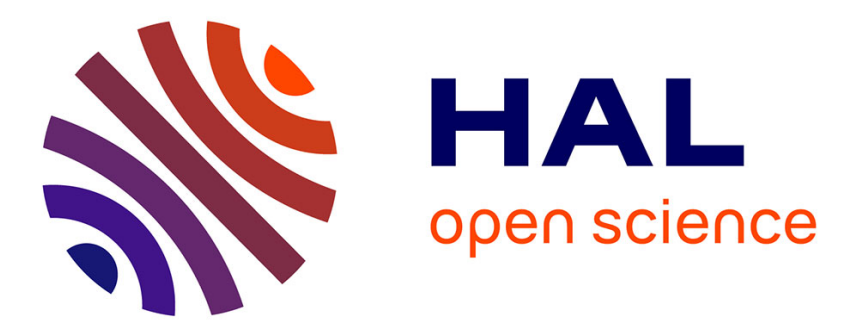

\title{
Reactivity and Mechanistic Issues in the Photocyclization of Dihalostyryl-Naphthalenes towards Halo-[4]helicenes: A Transposition on a Mallory Theme
} Kévin Martin, Caroline Melan, Thomas Cauchy, Narcis Avarvari

\section{- To cite this version:}

Kévin Martin, Caroline Melan, Thomas Cauchy, Narcis Avarvari. Reactivity and Mechanistic Issues in the Photocyclization of Dihalostyryl-Naphthalenes towards Halo-[4]helicenes: A Transposition on a Mallory Theme. ChemPhotoChem, 2021, 10.1002/cptc.202100215 . hal-03452633

\section{HAL Id: hal-03452633 \\ https://univ-angers.hal.science/hal-03452633}

Submitted on 27 Nov 2021

HAL is a multi-disciplinary open access archive for the deposit and dissemination of scientific research documents, whether they are published or not. The documents may come from teaching and research institutions in France or abroad, or from public or private research centers.
L'archive ouverte pluridisciplinaire HAL, est destinée au dépôt et à la diffusion de documents scientifiques de niveau recherche, publiés ou non, émanant des établissements d'enseignement et de recherche français ou étrangers, des laboratoires publics ou privés. 


\title{
Reactivity and Mechanistic Issues in the Photocyclisation of Dihalostyryl- Naphthalenes towards Halo-[4]helicenes: a Transposition on a Mallory Theme
}

Kévin Martin, Caroline Melan, Thomas Cauchy* and Narcis Avarvari*

Univ Angers, CNRS, MOLTECH-Anjou, SFR MATRIX, F-49000 Angers, France. E-mail: thomas.cauchy@univ-angers.fr; narcis.avarvari@univ-angers.fr

\begin{abstract}
One of the most straightforward strategies nowadays for the synthesis of carbo- and heterohelicenes is the oxidative photocyclisation of stilbene derivatives in the Mallory conditions. In this study, the reactivity of a series of 3,4-dihalostyryl-naphthalenes ( $\mathrm{Hal}=\mathrm{Br}, \mathrm{F}$ and $\mathrm{Cl}$ ) has been investigated in the Mallory conditions towards the corresponding halogenated [4] helicene compounds. The difluoro precursor afforded the two isomeric 2,3- and 1,2-difluoro[4]helicenes, resulting from the ring closure on the two possible positions of the substituted benzene ring, the dichloro compound led to the formation of a mixture of the two isomeric 2,3 and 1,2-dichloro-[4]helicenes together with the 2-mono-chloro derivative, while the dibromo precursor provided, unexpectedly, only 2,3-dibromo-[4]helicene and the 2-mono-bromo derivative. DFT calculations performed on the entire series of precursors, final helicenes and intermediate dihydrohelicenes, including the non-halogenated congeners, reveal the highly energetically favorable formation of a second dihydrohelicene intermediate following a $[1,9]$ hydrogen sigmatropic transposition. Whereas the existence of this transposed dihydrohelicene intermediate, more stable than the initially formed dihydrohelicene by fifteen to thirty $\mathrm{kcal} / \mathrm{mol}$, was hitherto "hidden" in the non-substituted series, it allows here to explain its re-aromatization through formal elimination of $\mathrm{HX}$ in order to provide the 2-mono-halogenated-[4]helicene derivatives.
\end{abstract}




\section{Introduction}

The oxidative photocyclisation of stilbenes into phenanthrenes [1] has been thoroughly investigated by Mallory who described its catalytical activation by iodine,${ }^{[2,3,4]}$ while latter on Katz et al. proposed improved conditions in order to reduce the number of side-products. ${ }^{[5]}$ This methodology has been successfully transposed to the synthesis of [n]helicenes, ${ }^{[6,7]}$ which are polyaromatic hydrocarbons with peculiar helical shape resulting from the ortho-condensation of at least four benzene rings. ${ }^{[8,9]}$ Their inherent helical chirality confers to helicenes exceptional chiroptical properties, such as huge optical rotations and strong circular dichroism activity, ${ }^{[10,11]}$ making them valuable precursors for molecular and supramolecular materials. ${ }^{[12,13,14]}$ The smallest member of the [n]helicene series is [4]helicene, whose synthesis involves the oxidative photocyclisation of 2-styryl-naphthalene $\mathbf{A}$ which can be used as a mixture of cis and trans isomers, the latter providing the former under irradiation (Scheme 1). As Mallory pointed out, both possible cyclized dihydro intermediates A1 and A2 are formed, yet the benzophenanthrene A1, resulting from cyclisation in position $a_{1}$, benefits of aromatic resonance stabilization of one benzene ring, which is absent in the anthracene intermediate $\mathbf{A 2}$, formed upon ring closure in position $a_{2} \cdot{ }^{[4]}$ Consequently, the reversed ring opening of $\mathbf{A} \mathbf{2}$ back to the corresponding cis-stilbene is much more favored than that of A1.

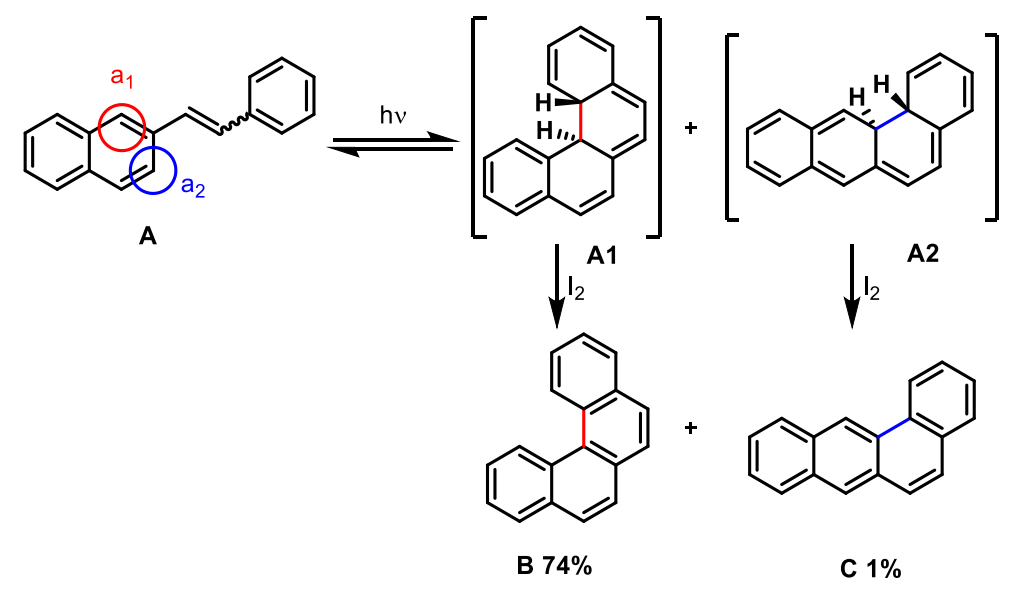

Scheme 1. Reactivity of the positions $a_{1}$ and $a_{2}$ for the [4]helicene formation under the Mallory conditions.

If the amount of iodine is large enough then the final benzo-anthracene compound $\mathbf{C}$ can be isolated as by-product (1\%), while with lower iodine concentrations its detection becomes more problematic and in general only the [4] helicene compound $\mathbf{B}$ is isolated, thus allowing a very high regioselectivity for this reaction. The steric hindrance provided by the presence of substituents on the benzene ring does not seem to play an important role on the regioselectivity of the photocyclization of stilbenes or 2-styryl-naphthalenes, suggesting that the transition state 
occurs early along the reaction coordinate when the geometry closely relates to that of the uncrowded excited state stilbene. ${ }^{[4]}$ This issue was especially investigated in the case of stilbenes, but also 2-styryl-naphthalenes, containing a $\mathrm{CH}_{3}, \mathrm{Cl}$ or $\mathrm{CF}_{3}$ substituent in the meta position of the benzene ring, where practically equimolar mixtures of the two regioisomers have been obtained. ${ }^{[15]}$ Intriguingly, the case of the bromine substituent in the meta position in a series of stilbenes has been only mentioned in a few reports describing the preparation of the corresponding phenanthrenes with the $\mathrm{Br}$ substituent in position 2, without any evidence for the formation of the other possible isomer with $\mathrm{Br}$ in position 4, which is one of the two inner positions in phenanthrenes. ${ }^{[16,17,18]}$ The authors thus concluded that the ring closure reaction was highly regioselective, in spite of the yields observed for the various 2-Br-phenanthrenes reaching up to a maximum of $50 \%$. When the $\mathrm{Br}$ substituent is located in the para position, no regioselectivity issues occur. ${ }^{[19]}$

In the course of our own investigations on the synthesis and reactivity of bromo[4]helicenes, ${ }^{[20,21,22]}$ we have performed the oxidative photocyclisation of 3,4-dibromostyrylnaphthalene 1a in the Mallory conditions to obtain 2,3-dibromo-[4] helicene 2a, which initially turned out to be the only isolated [4] helicene (Scheme 2). ${ }^{[23]}$

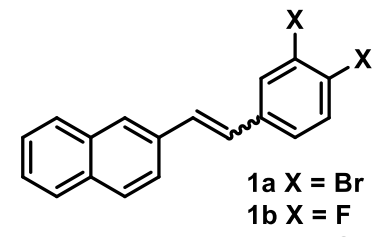

1c $X=C l$

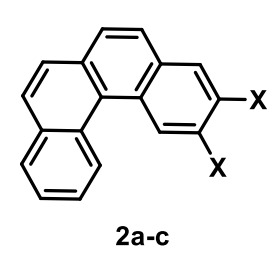

Scheme 2. 3,4-dihalostyryl-naphthalene and corresponding 2,3-dihalo[4]helicene.

Puzzled by this apparent high regioselectivity of the cyclisation we have decided to shed light on its origin. We present herein our systematic combined experimental and theoretical study on the photocyclisation of 3,4-dihalostyryl-naphthalenes 1a-c $(\mathrm{X}=\mathrm{Br}, \mathrm{F}, \mathrm{Cl})$ towards corresponding halo-[4] helicenes, evidencing a halogen depending HX elimination reaction as a consequence of a hitherto unrevealed hydrogen sigmatropic [1,9]-transposition.

\section{Results and discussion}

\section{Reactivity of dihalostyryl-naphthalenes in oxidative photocyclisation conditions}

In a first instance, we have prepared the dibromostyryl-naphthalene 1a (Scheme 3) by the twostep pathway procedure previously described by us. ${ }^{[23]}$ The first step corresponds to the preparation of the phosphonium salt $\mathbf{3}$ starting from 2-bromomethyl naphthalene and 
triphenylphosphine. The subsequent step is a Wittig reaction between $\mathbf{3}$ and 3,4-dibromobenzaldehyde, which afforded the corresponding stilbene 1a as mixture of cis/trans isomers.

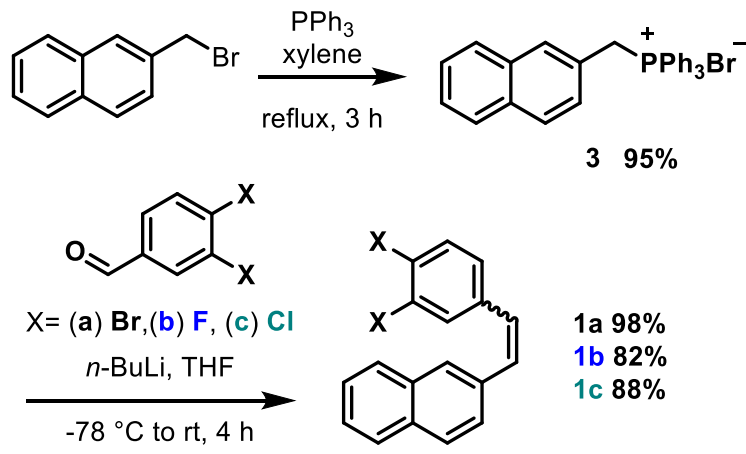

Scheme 3. Preparation of dihalostyryl-napthalene 1a-c.

Single crystals of compound 1a, suitable for X-ray diffraction, were obtained by recrystallization in a mixture of pentane/dichloromethane (9/1) (Table S1). Analysis of the structure shows that the trans isomer crystallises in the centrosymmetric space group $P 2{ }_{1} / c$ from the monoclinic system, with half independent molecule in the asymmetric unit, containing the naphthyl and dibromo-benzene groups nested in each other, being equally disordered over two positions (Figure S1 and Table S2). The molecule is perfectly planar and because of the statistical disorder it is not straightforward to disclose short intermolecular distances in the packing (Figure S2). In our initial report dedicated to the synthesis and properties of the first tetrathiafulvalene-helicene (TTF-Hel) derivatives as precursors for chiral electroactive materials, ${ }^{[14,24]}$ we have described the oxidative photocyclisation of $\mathbf{1 a}$ as providing exclusively the 2,3-dibromo-[4]helicene $\mathbf{2 a}$ (Scheme 4), ${ }^{[23]}$ in agreement with similar regioselectivity observed for other meta-substituted bromo-stilbenes. ${ }^{[16,17,18]}$ The dibromo-helicene $2 \mathbf{a}$ was subsequently used in a bis-Stille coupling reaction to provide a protected helicene-bis(thiolate). However, a closer inspection now of the reaction products of the Mallory reaction on 1a reveals that, besides $\mathbf{2 a}$, the monobromo derivative $\mathbf{4 a}$ is also formed in a ratio $\mathbf{2 a : 4 a}$ of $\sim 2: 1$ (Scheme 4). For comparison purposes, 4a has been deliberately synthesized starting from a mixture of the monobromo stilbenes $(E)$ - and (Z)-1-(p-bromophenyl)-2-(2-naphthyl)ethylene (see the Experimental Section). In fact, in stilbene 1a, the positions $a_{1}$ et $a_{2}$ on the naphthalene part and the positions $b_{1}$ and $b_{2}$ on the phenyl ring can, in principle, react in a six electron photocyclisation reaction. Thereby, in theory, four products can be formed, but in our case only 2a and 4a were observed, resulting from the ring closure in position $a_{1}$ on naphthalene and $b_{2}$ and $b_{1}$, respectively, on phenyl. Moreover, cyclisation in $b_{1}$ is accompanied, unexpectedly, by the elimination of the bromine substituent in position 1 , thus preventing the isolation of 1,2- 
dibromo-[4]helicene, which was never observed in the actual conditions. Note that the formation of both helicenes is triggered by the aromatization of the dihydro intermediates, in the case of $\mathbf{2 a}$ two hydrogen atoms being eliminated, while in the case of $\mathbf{4 a}$ a $\mathrm{HBr}$ molecule being formally removed.

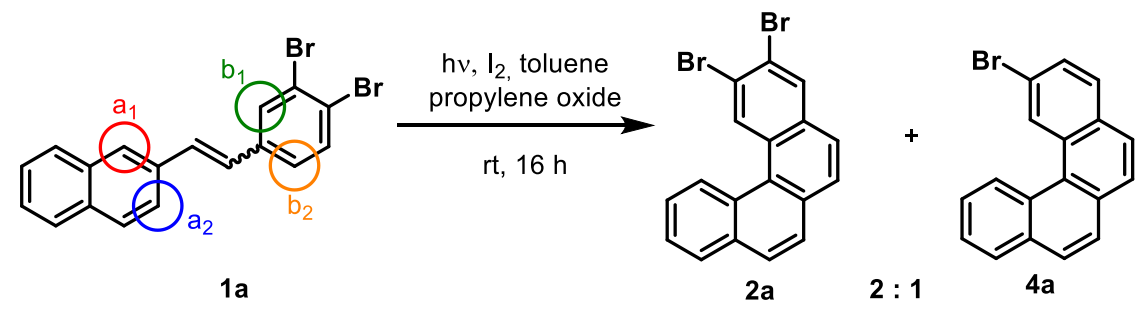

Scheme 4. Possible cyclisation sites and isolated products in the case of 1a.

At a first glance, it would be logical to think that the most favourable position for cyclisation is $a_{2}$ due to the minimisation of the steric hindrance in the final product. However, in practice, the helicene, resulting from cyclisation in $a_{l}$, is formed exclusively or in a large excess, as clearly established by Mallory in the case of photocyclisation of stilbenes and styryl-naphthalenes towards phenanthrenes and [4]helicenes, respectively. ${ }^{[4]}$ Accordingly, in the experimental conditions we have used, the anthracene compound was not formed. Moreover, as pointed out above, the formation of 1,2-dibromo-[4]helicene did not take place, although the formation of 4a can only be explained by cyclisation in position $b_{1}$, which would afford the former as "normal" Mallory compound, yet formal elimination of $\mathrm{HBr}$ takes place to provide $\mathbf{4 a}$.

In order to verify this assumption, we decided to "force" the cyclisation in position $b_{1}$ by blocking the position $b_{2}$ with a methyl group (Scheme 5). Thus, instead of using 3,4-dibromobenzaldehyde, we have used 4,5-dibromo-2-methylbenzaldehyde for the Wittig reaction to obtain the dibromo-methyl-styryl-naphthalene 5. While the yield of the subsequent photocyclisation was globally low, the only isolated helicene was the monobromo derivative $\mathbf{6}$, with no evidence of the dibromo compound 7. 

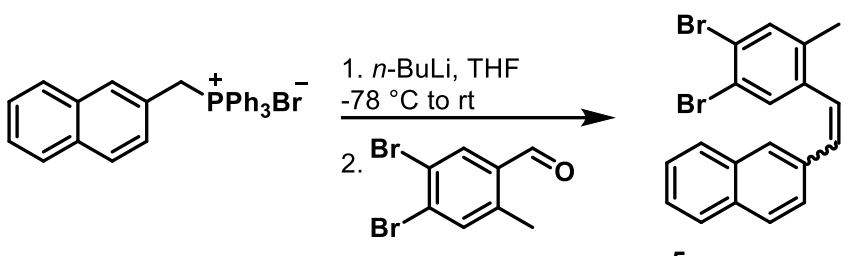

5

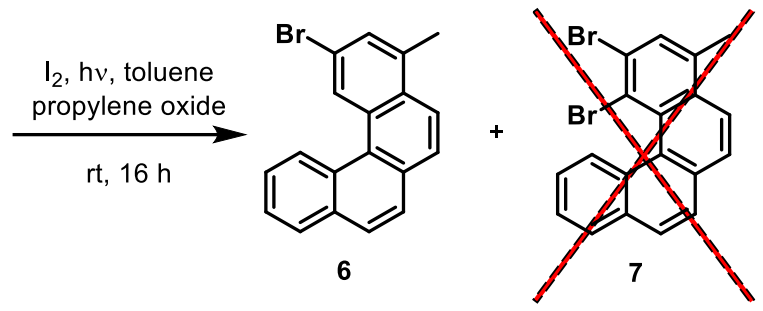

Scheme 5. Blocking the position $b_{2}$ in the stilbene precursor 5 .

Once again, the formation of $\mathbf{6}$ should involve cyclisation in positions $a_{1}$ and $b_{1}$ followed by formal elimination of $\mathrm{HBr}$.

Hypothesizing that this unprecedented elimination of HX should be halogen dependent, we have decided to extend the scope of the reaction towards difluoro and dichloro derivatives $\mathbf{1 b}$ and 1c, since the Mallory reaction is normally compatible with fluoro and chloro substituents. ${ }^{[1,4,25]}$ Accordingly, starting from the phosphonium salt $\mathbf{3}$ and using 2,3-difluoro and 2,3-dichlorobenzaldehyde we have obtained the two stilbenes $\mathbf{1 b}$ and $\mathbf{1 c}$ as a mixture of $Z$ and $E$ isomers (Scheme 3). Subsequent photocyclisation of $\mathbf{1 b}$ and $\mathbf{1 c}$ provided strikingly different results compared to $\mathbf{1 a}$ (Scheme 6).

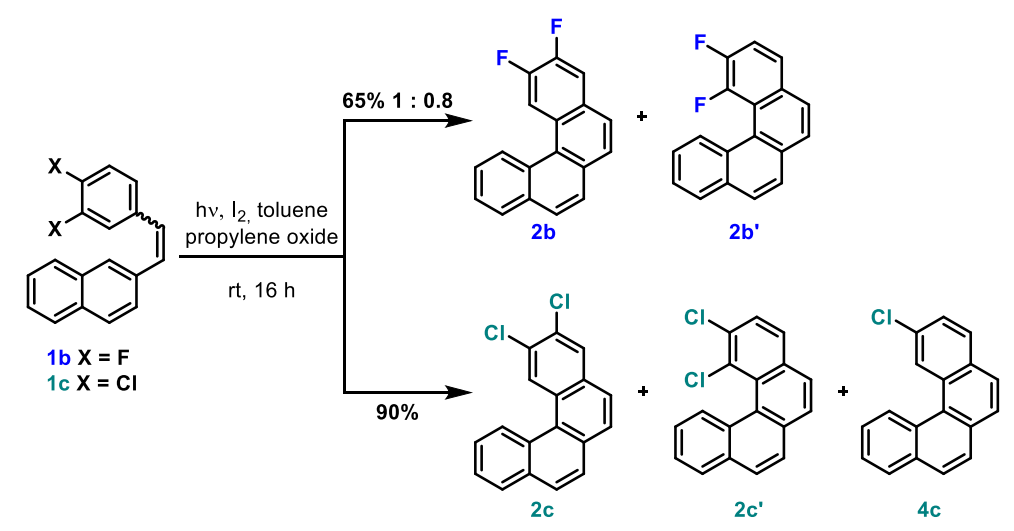

Scheme 6. Photocyclisation of difluoro- and dichloro-styryl-naphthalenes $\mathbf{1 b}$ and $\mathbf{1 c .}$

In the case of the fluoro compound, mass spectrometry analysis of the crude reaction products showed only one peak at $\mathrm{m} / \mathrm{z}=264$ corresponding to the bis-fluorinated compound, meaning that there is no release of fluorine during the cyclisation process. In the ${ }^{19} \mathrm{~F}$ NMR spectra two sets of doublets corresponding to two difluoro compounds with fluorine-fluorine couplings are 
observed. Using COSY ${ }^{1} \mathrm{H}$ NMR experiments we were able to attribute the different proton signals and in addition the ratio between the two molecules (see the SI). Thereby, 2,3-difluoro[4] helicene $\mathbf{2 b}$ formed together with 1,2-difluoro-[4] helicene $\mathbf{2 b}$ ' in a 1:0.8 ratio. Despite the quasi-similar polarity of the two isomers, we have been able to separate them on preparative thin layer chromatography (TLC) and thus to confirm the ratio between the two molecules.

In the case of the chloro compound, mass spectrometry showed two peaks at $\mathrm{m} / \mathrm{z}=260$ and 296, suggesting the presence of dichloro and monochloro [4] helicenes. ${ }^{1} \mathrm{H}$ NMR measurements confirmed the presence of three compounds, one easily identified as 2-chloro-[4]helicene 4c, which was already described in the literature. ${ }^{[26]}$ The two other compounds are the isomeric 1,2- and 2,3-dichloro-[4]helicene 2c and 2c', respectively. Unfortunately, we have not been able to separate the mixture of these three compounds and the complexity of the ${ }^{1} \mathrm{H}$ NMR did not allow us to accurately determine the ratio between them. However, according to the previous results, we can suppose that 1,2-dichloro-[4] helicene 2c' and 2-chloro-[4] helicene $\mathbf{4 c}$ together, both resulting from ring closure in position $b_{1}$, represent maximum $50 \%$ and 2,3dichloro-[4]helicene $2 \mathrm{c}$ minimum $50 \%$ of the helicene products.

In summary, in this halogen series, the difluoro stilbene $\mathbf{1 b}$ leads to the formation of the normally expected Mallory difluoro-helicenes with only a very slight selectivity in favour of the 2,3-substituted compound, no fluorine release being observed. Thus, it seems that the steric hindrance does not play a significant role here. On the contrary, the photocyclisation of the dibromo precursor 1a affords, beside the expected 2,3-dibromo derivative 2a, the monobromohelicene $\mathbf{4 a}$, as a result of cyclisation in position $b_{1}$ and formal elimination of $\mathrm{HBr}$ instead of $\mathrm{H}_{2}$. In fact, in the Mallory mechanism, the two hydrogen atoms are removed as HI upon the action of $I_{2}$, radical species being involved. A mixed situation is observed in the case of the dichloro precursors 1c, here the formation of the normal Mallory 2,3-dichloro-helicene $\mathbf{2 c}$ and 1,2-dichloro-helicene $\mathbf{2} \mathbf{c}^{\prime}$ being in competition with the $\mathrm{HCl}$ formal elimination providing $\mathbf{4 c}$. At a first sight, it appears that the observed distribution of the reaction products in the three cases is dictated by the $\mathrm{C}-\mathrm{X}$ bond homolysis value ${ }^{[27]}$ also linked to the nucleofuge ability of the three halogens. However, it is clear that the elimination of HX cannot occur from the initially formed dihalo-dihydro-[4]helicene intermediate of A1 type (Scheme 1), but some rearrangement has to occur. In order to shed light on a plausible mechanism explaining the observed reactivity of precursors 1a-c we have performed DFT calculations on the whole series of halogenated styryl-naphthalene precursors, dihydrohelicene intermediates and final helicenes. For comparison purposes the same calculations have been conducted on the unsubstituted 2-styryl-naphthalene $\mathbf{1 .}$ 


\section{Theoretical study}

A theoretical approach has been set to understand the differences in reactivity among the different compounds, the ultimate objective being the rationale of the release of a bromine atom to provide the 2-bromo-[4]helicene $4 \mathbf{a}$ while the photocyclisation should afford 1,2-dibromo[4]helicene. Theoretical studies concerning the photochemical synthesis of helicenes are scarce. For example, a frontier molecular orbital (FMO) and condensed Fukui functions study based on DFT calculations was reported by Caronna et al. for the synthesis of monoaza[5]helicenes. ${ }^{[28]}$ More reports exist on the photochemical synthesis of phenanthrene, among which worth noting are recent experimental and theoretical investigations on the photoisomerization and photocyclization mechanisms. ${ }^{[29,30,31]}$

For our study, to describe the photocyclization mechanism, several structures (minima and some transition states) have been computed for the difluoro, dichloro, dibromo and also unsubstituted 2-styryl-naphthalene compounds, the latter serving as a reference model (Figures S3-S83 and Tables S3-S43). The proposed reaction mechanism, which seems the most likely, can be described using four minima. Figure 1 shows the optimized geometries for those four states of the unsubstituted 2-styryl-naphthalene compound, starting with the cis-stilbene $\mathbf{1}$, followed by the cyclized non aromatic form dihydrohelicene (denoted DH for the whole series), the intermediate resulting after a [1,9]-H sigmatropic transposition (denoted DHS) and then ending with the [4]helicene 2 (see Scheme 1).
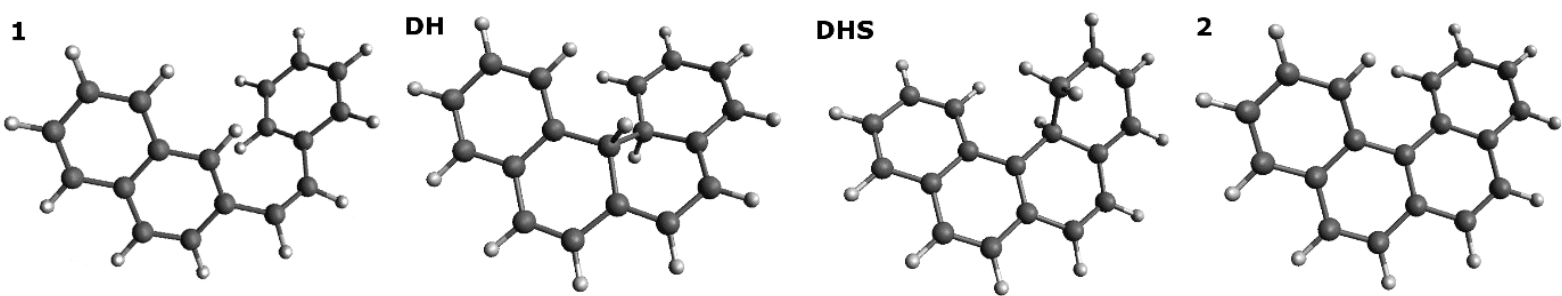

Figure 1. Selected topologies to represent the photocyclization reaction. From left to right, cis-stilbene (1), transdihydrohelicene (DH), [1,9]-H sigmatropic rearrangement product (DHS) and [4]helicene (2).

We have started by computing the ground states of the cis-stilbene precursors. Their geometries have been optimized with a hybrid functional (PBE0) and an augmented triple zeta basis set (see Computational details). Since the photocyclization is an electrocyclic reaction under photochemical conditions, its mechanism should be described by considering orbital symmetry reasoning based on the LUMO of the ground state within the Woodward-Hoffmann rules 
framework. ${ }^{[32,33]}$ It is important to note here that we have also calculated the Fukui functions and that their description of the nucleophilic and electrophilic regions did not bring any more information than the study of the FMO. In a similar approach, it would have been possible to use the Wiberg binding indices of the first singlet state. ${ }^{\left[{ }^{34]}\right.}$ Accordingly, the calculated LUMO within the cis-stilbene series $\mathrm{H}(\mathbf{1}), \mathrm{Br}(\mathbf{1 a}), \mathrm{F}(\mathbf{1 b})$ and $\mathrm{Cl}(\mathbf{1 c})$ are represented in Figure 2, by keeping the orientation of the molecules from Figure 1. We can firstly note that in all systems, the ground state geometries present a dihedral angle (around $35^{\circ}$ ) between the naphthalene and benzene moieties. It allows for a better overlap between the two carbon atoms involved in the $a_{1}$ pathway cyclization. Secondly, the coefficients for the $a_{2}$ position (highlighted in Figure 2), that could generate the benzanthracene isomers (Schemes 1 and 4), are clearly negligible compared to those in position $a_{l}$. Therefore, for our systems, the photocyclization leads exclusively to helicenes. We can also note that the substitution with halogen atoms in positions 3,4 of the benzene ring do not modify the overall topology of the LUMO. For all di-halogenated compounds the coefficients on the $b_{1}$ and $b_{2}$ positions are quite similar (see the SI), suggesting that cyclization on both positions should occur in photochemical conditions (Scheme 4). We could add here that the HOMO's correspond to antibonding interactions between the carbons involved in the cyclization reaction (see full molecular reports in the SI).
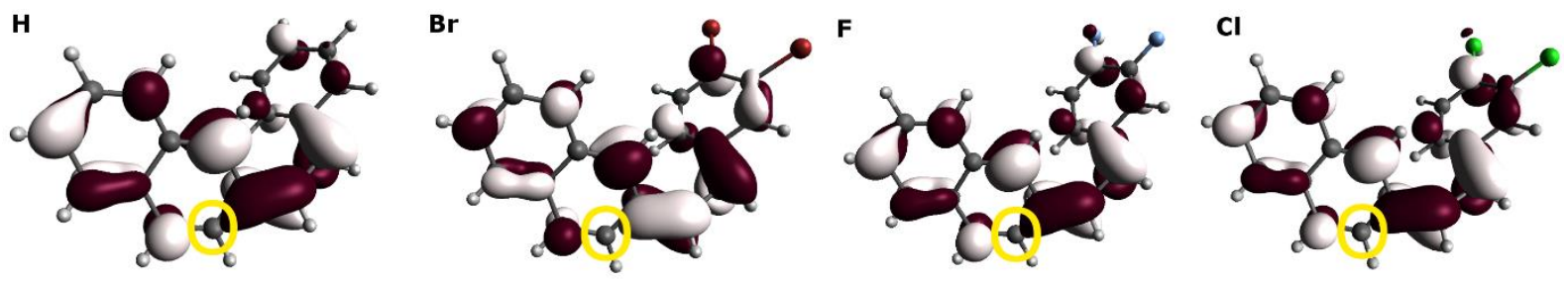

Figure 2. LUMO representation for the calculated cis-stilbenes $\mathbf{1}$ and $\mathbf{1 a - 1 \mathbf { c }}$ from left to right. The $a_{2}$ position is highlighted by the golden circle.

As mentioned above, the calculated stilbenes correspond to the optimal cis forms for the photocyclization reaction. The UV-visible lamp used has an emission range between 250 and $577 \mathrm{~nm}$. The UV-visible absorption properties of dibromo derivative cis-1a have been simulated by TD-DFT calculations (see Computational details). Figure 3 shows the theoretical UV-visible absorption spectrum along with the electron density difference between the first excited state and the ground state, corresponding to an absorption band around $350 \mathrm{~nm}$. This first excitation characterizes the HOMO $\rightarrow$ LUMO transition and the electron density difference map confirms the involvement of the corresponding carbons for the photocyclization and adds the information that upon excitation the $a_{1}$ position is electron deficient. 

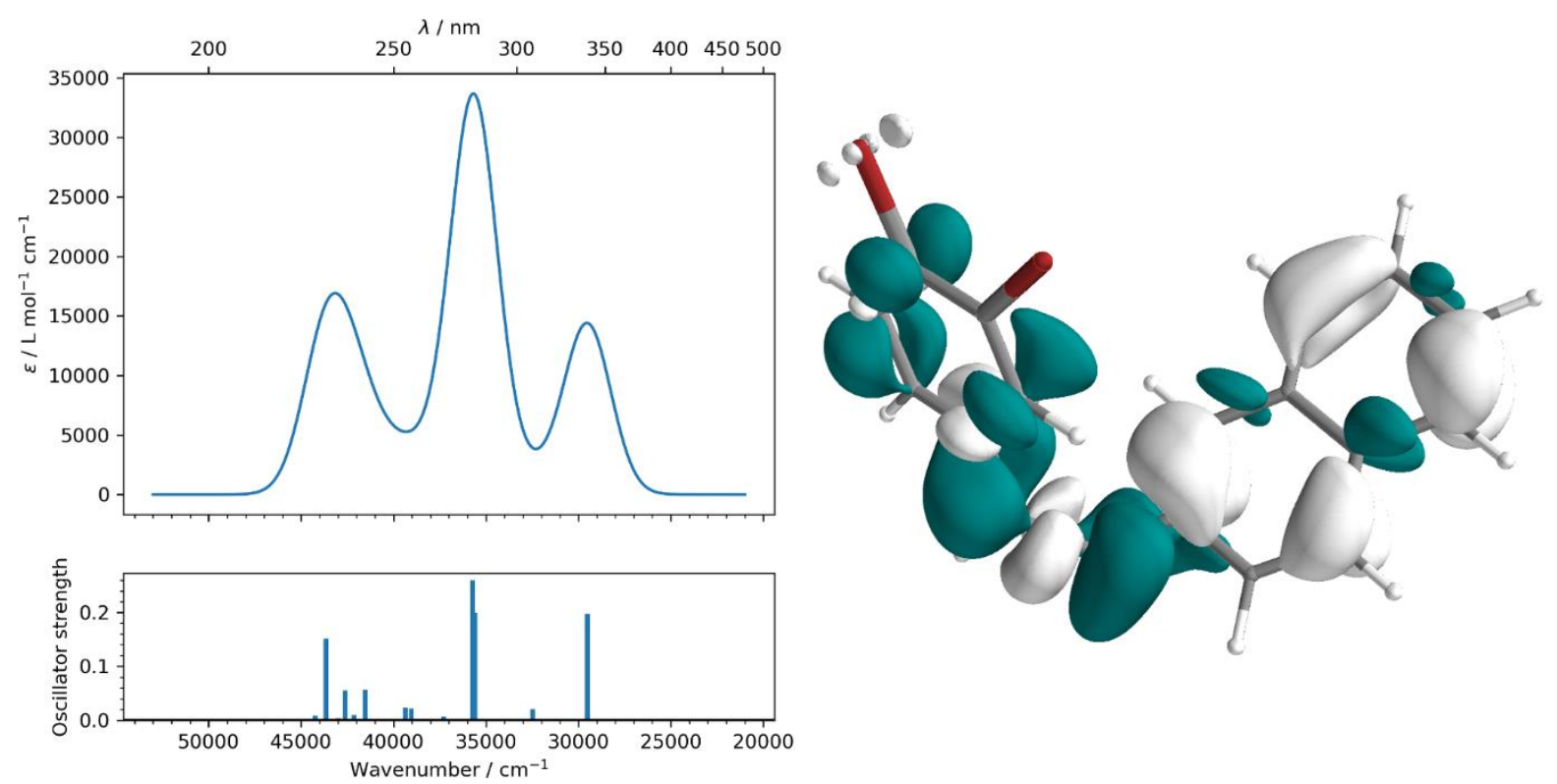

Figure 3. Simulated absorption spectra of compound 1a and oscillator strengths of the vertical transitions (left). Electronic density difference calculated for the first transition (right). The blue surface represents the excited electron and the white surface the hole (density decrease upon excitation).

The geometry and the FMOs of the ground state indicate a cyclization that leads to a trans configuration of the dihydrohelicene hydrogens (see Figure 1) upon a conrotatory ring closure. The Gibbs free energies of the calculated minima are reported in Table 1. The profile of this reaction is similar whatever the substitution (hydrogen, bromine, chlorine or fluorine). All stilbenes have an energy $12 \mathrm{kcal} / \mathrm{mol}$ higher than the 2,3-disubstituted helicenes. The absorption band around $350 \mathrm{~nm}$ corresponds to an energy of the order of $80 \mathrm{kcal} / \mathrm{mol}$, which is much higher than the energy of the transition state corresponding to the cyclisation of cis-stilbene to dihydrophenanthrene. ${ }^{35}$ The reaction intermediate, trans-dihydrohelicene $\mathrm{DH}$, is therefore clearly reachable.

Table 1. Gibbs free energies differences in $\mathrm{kcal} / \mathrm{mol}$ along the photocyclization reactions. The energy reference is set to the 2,3-dihalogenohelicene or the energy of the carbohelicene for the model compound.

\begin{tabular}{|c|c|c|c|c|}
\hline compound & Stilbene (1) & $\begin{array}{c}\text { trans- } \\
\text { dihydrohelicene } \\
\text { (DH) }\end{array}$ & $\begin{array}{c}\text { supra / antara } \\
\text { [1,9] } \\
\text { sigmatropy } \\
\text { (DHS) }\end{array}$ & $\begin{array}{c}\text { Helicene }\left(+\mathbf{H}_{2}\right. \\
\text { / +HX) }\end{array}$ \\
\hline Carbo & 12 & 44 & 23 & 0 \\
\hline 1,2-dibromo & 12 & 47 & $30 / 18$ & $10 /-20$ \\
\hline 2,3-dibromo & 12 & 43 & 20 & 0 \\
\hline 1,2-dichloro & 12 & 47 & $31 / 21$ & $9 /-20$ \\
\hline
\end{tabular}




\begin{tabular}{|l|c|c|c|c|}
\hline 2,3-dichloro & 12 & 43 & 21 & 0 \\
\hline 1,2-difluoro & 12 & 46 & $31 / 23$ & $4 /-23$ \\
\hline 2,3-difluoro & 12 & 43 & 23 & 0 \\
\hline
\end{tabular}

Here is where, i.e. evolution of the intermediate trans-dihydrohelicenes (DH), the mechanism diverges from the phenanthrenes studies. If one considers a direct elimination of hydrogen to helicenes, one cannot explain the formation of the monobrominated compounds $\mathbf{4 a}$ (Scheme 4) and 6 (Scheme 5). As can be observed in Table 1, that there is no major difference in the energy profiles between the 1,2 or 2,3 di-substituted compounds. The reaction must therefore involve a step that particularly affects position 1 . Looking at the frontier molecular orbitals of the dihydrohelicenes reaction intermediate (Figure 4), one can see that the hydrogen atoms of the $\mathrm{sp}^{3}$ carbons do indeed have coefficients in the HOMO and the LUMO. Considering a thermal process, the red lobe of the proton in the HOMO can overlap with the large red lobe on position 1. This corresponds to a thermally allowed [1,9]-H sigmatropic rearrangement with a suprafacial shift. A mechanism involving a tandem photocyclization/[1,9]-H sigmatropic rearrangement has been recently proposed for the photochemical transformation of diarylethenes containing five-membered heterocyclic rings. ${ }^{[36]}$ Note that since we are under irradiation, an [1,9]-H antara transposition cannot be discarded. The LUMO topology allows for such transposition as well.
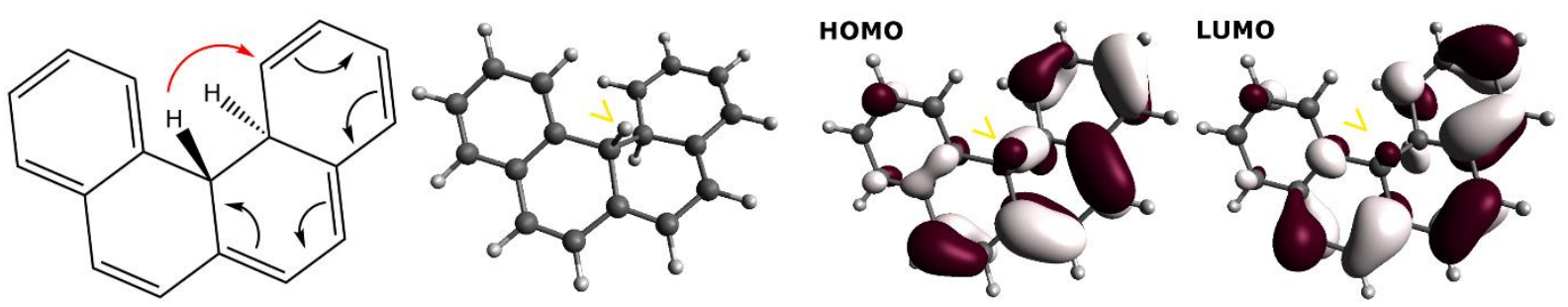

Figure 4. Proposed [1,9]-H sigmatropic rearrangement, structure of the trans-dihydrohelicene (DH) along with the HOMO and LUMO representation.

The energy stabilization associated with the transposition is rather important, reaching up between fifteen to thirty $\mathrm{kcal} / \mathrm{mol}$ (see Table 1 ). We thus hypothesize that prior to any rearomatization reaction through $\mathrm{HI}$ formation thanks to the presence of $\mathrm{I}_{2}$, the initial transdihydrohelicenes DH systematically evolve towards the more stable sigmatropically transposed intermediates DHS (Figure 4). Consequently, in the case of the 1,2 disubstituted compounds, this rearrangement provides intermediate DHS allowing for a competition between the elimination of either $\mathrm{H}_{2}$ (actually $\mathrm{HI}$ in the presence of $\mathrm{I}_{2}$ ) or $\mathrm{HX}$ to afford the final helicenes. 
If we reason on the basis of the Gibbs free energies of the products, the elimination of $\mathrm{HX}$ is always favored over that of $\mathrm{H}_{2}$ whatever the halogen (Table 1). The experimentally observed difference between the three halogens must come from the energy barrier associated with this elimination. The frontier molecular orbitals of the 1,2-dibromo compound DHS after either the suprafacial or antarafacial sigmatropic rearrangement (Figure 5) show coefficients on the hydrogen and on the $\sigma^{*}$ of the $\mathrm{C}-\mathrm{Br}$ bond both in the HOMO and LUMO favorable to either a syn or an anti elimination. Indeed, the elimination of $\mathrm{HX}(\mathrm{X}=\mathrm{Cl}, \mathrm{F})$ in syn without the intervention of an oxidizing agent has been studied experimentally and theoretically in the case of simple $\mathrm{Cl}$ and $\mathrm{F}$ substituted ethane derivatives and would present energy barriers of the order of $60 \mathrm{kcal} / \mathrm{mol}$ for $\mathrm{HCl}$ and $\mathrm{HF}$ elimination. ${ }^{[37,38]}$ However, in our case, the presence of $\mathrm{I}_{2}$ in the reaction mixture very likely promotes the elimination of $\mathrm{HI}$ and $\mathrm{IBr}$. In the case of the unsubstituted or the 2,3-disubstituted compounds the final helicene compounds are the same regardless whether the elimination of two molecules of $\mathrm{HI}$ occurs from the initially formed DH or the transposed forms DHS. However, the greater stability of the latter than the former points out towards the systematic formation of DHS intermediates which then afford the final helicenes upon HI elimination.
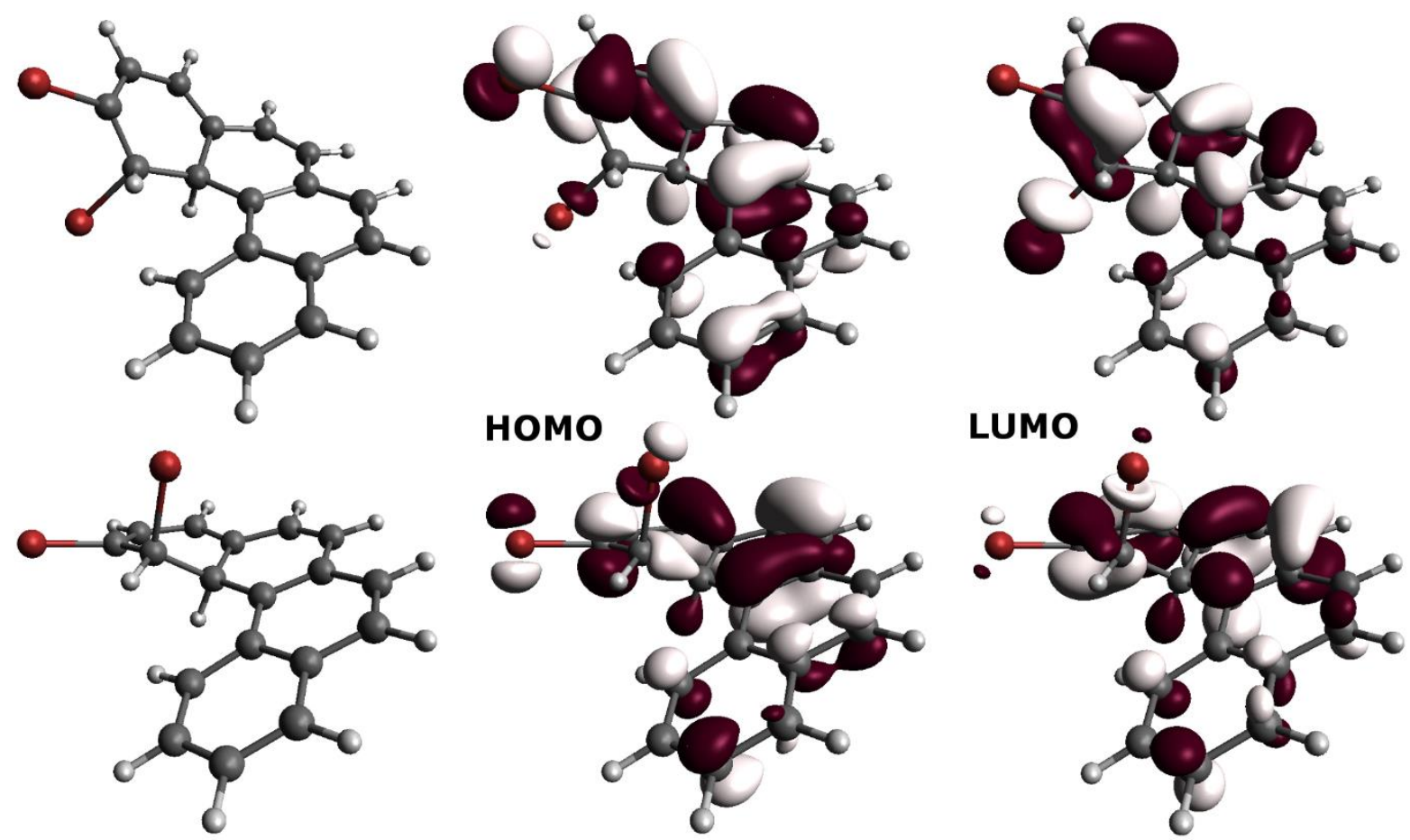

Figure 5. Frontier molecular orbitals after a suprafacial (top) and antarafacial (bottom) [1,9]-H sigmatropic rearrangement for the dibromo DHS intermediate. 


\section{Conclusions}

In conclusion, we have demonstrated for the first time throughout a combined experimental/theoretical study involving the oxidative photocyclisation of 3,4-dihalostyrylnaphthalenes towards [4]helicene derivatives that a hitherto unrevealed [1,9]-H sigmatropic transposition takes place prior to the re-aromatization of dihydrohelicene intermediates. This rearrangement, energetically favored for the entire series including the non-halogenated compound, explains here the experimental formation of mono-bromo and mono-chloro [4]helicenes. The competition between formal $\mathrm{HX}$ and $\mathrm{H}_{2}$ elimination from the transposed dihalogenated dihydrohelicenes is very likely triggered by the nucleofuge ability of the three halogens following the order $\mathrm{Br}>\mathrm{Cl}>\mathrm{F}$, thus explaining the exclusive formation of monobromo derivative together with 2,3-dibromo-[4]helicene, the mixture of mono-chloro and two isomeric 1,2- and 2,3-dichloro-[4]helicenes and, finally, the mixture of 1,2- and 2,3-difluoro[4]helicenes. This study, besides the preparation of new dihalo-[4]helicene compounds, sheds light on an unknown important aspect of the Mallory reaction, applied here to the helicene synthesis, which can explain "unexpected" regioselectivity and reactivity issues. Accordingly, we postulate that such $[1,9]-\mathrm{H}$ sigmatropic transpositions providing much more stable dihydro intermediates is a general feature of the Mallory reaction which has been overlooked so far.

\section{Experimental}

\subsection{Materials and methods}

Reactions were carried out under nitrogen, dry solvents were obtained from distillation machines. Nuclear magnetic resonance spectra were recorded on a Bruker Avance DRX 300 spectrometer operating at $300 \mathrm{MHz}$ for ${ }^{1} \mathrm{H}$ and $76 \mathrm{MHz}$ for ${ }^{13} \mathrm{C}$. Chemical shifts are expressed in parts per million ( $\mathrm{ppm}$ ) downfield from external TMS. The following abbreviations are used: s, singlet; d, doublet; dq, doublet of quadruplets; m, massif. MALDI- TOF MS spectra were recorded on Bruker Biflex-IIITM apparatus, equipped with a $337 \mathrm{~nm} \mathrm{N_{2 }}$ laser. Elemental analysis were recorded using Flash 2000 Fisher Scientific Thermo Electron analyzer.

\subsection{Synthesis}

2-(3,4-dibromostyryl)naphthalene (1a): In a flask under argon atmosphere the phosphonium salt 3 (4.0 g, $8.27 \mathrm{mmol}, 1$ equiv) was dissolved in $80 \mathrm{~mL}$ of distilled THF and cooled at $-78^{\circ} \mathrm{C}$. Then, $n$-BuLi (3.3 mL, $8.69 \mathrm{mmol}, 2.6 \mathrm{M}$ in hexane, 1.05 equiv) was added giving an orange solution. After 15 minutes at $-78{ }^{\circ} \mathrm{C}$ the solution was left to warm at RT until the mixture 
became red. Then, it was cooled at $-78{ }^{\circ} \mathrm{C}$ and the 3,4-dibromobenzaldehyde $(2.2 \mathrm{~g}, 8.27 \mathrm{mmol}$, 1 equiv) was added. After 15 minutes at $-78{ }^{\circ} \mathrm{C}$, it was left to warm at RT for $3 \mathrm{~h}$. The mixture was then concentrated and purified by chromatography with petroleum ether as eluent. $3.15 \mathrm{~g}$ (98\% yield) of $\mathbf{1 a}$ (cis/trans mixture) were obtained as a white powder. ${ }^{1} \mathrm{H}$ NMR $(300 \mathrm{MHz}$, Chloroform- $d$ ): cis $\delta=7.73-7.82(\mathrm{~m}, 3 \mathrm{H}), 7.69(\mathrm{~d}, 1 \mathrm{H}, J=8.6 \mathrm{~Hz}), 7.57$ (sd, $1 \mathrm{H}, J=1.8 \mathrm{~Hz})$, $7.44-7.50(\mathrm{~m}, 2 \mathrm{H}), 7.41(\mathrm{~d}, 1 \mathrm{H}, J=8.3 \mathrm{~Hz}), 7.31(\mathrm{dd}, 1 \mathrm{H}, J=8.5,1.6 \mathrm{~Hz}), 7.06(\mathrm{dd}, 1 \mathrm{H}, J=$ $8.2,1.9 \mathrm{~Hz}), 6.84(\mathrm{~d}, 1 \mathrm{H}, J=12.2 \mathrm{~Hz}), 6.53(\mathrm{~d}, 1 \mathrm{H}, J=12.2 \mathrm{~Hz})$. trans $\delta=7.82-7.87(\mathrm{~m}, 6 \mathrm{H})$, $7.72(\mathrm{dd}, 1 \mathrm{H}, J=8.6, .5 \mathrm{~Hz}), 7.61(\mathrm{~d}, 1 \mathrm{H}, J=8.2 \mathrm{~Hz}), 7.47-7.51(\mathrm{~m}, 2 \mathrm{H}), 7.36(\mathrm{dd}, 1 \mathrm{H}, J=$ 8.3, $2.0 \mathrm{~Hz}), 7.28(\mathrm{~d}, 1 \mathrm{H}, J=16.3 \mathrm{~Hz}), 7.11(\mathrm{~d}, 1 \mathrm{H}, J=16.3 \mathrm{~Hz}) .{ }^{13} \mathrm{C}$ NMR $(76 \mathrm{MHz}$, Chloroform- $d$ ): cis $\delta=138.1,134.0,133.9,133.5,133.3,132.8,132.2,129.0,128.2,128.0$, $127.9,127.8,127.7,126.5,126.3,124.7,123.2$. trans $\delta=138.0,134.0,133.8,133.4,133.3$, $132.7,132.1,128.9,128.2,128.0,127.80,127.75,127.7,126.4,126.2,124.6,123.1$. MS (EI) $\mathrm{m} / \mathrm{z}=385.8\left(\mathrm{M}^{+}\right), 305.9\left([\mathrm{M}-\mathrm{Br}]^{+}\right), 228.0\left([\mathrm{M}-2 \mathrm{Br}]^{+}\right) ;$calculated $=385.93$.

2-(3,4-difluorostyryl)naphthalene (1b): In a $50 \mathrm{~mL}$ flask under argon was dissolved 3 (2.0 g, $4.14 \mathrm{mmol}, 1$ equiv) in dry THF (25 mL). At $-78{ }^{\circ} \mathrm{C}, n$-BuLi $(2.59 \mathrm{~mL}, 4.14 \mathrm{mmol}, 1.6 \mathrm{M}$ in hexane, 1.05 equiv) was slowly added and the mixture turned from white to red. After 15 min stirring, the mixture reached the RT and was stirred for additional $15 \mathrm{~min}$. The mixture was then cooled down at $-78{ }^{\circ} \mathrm{C}$ and 3,4-difluorobenzaldehyde ( $0.59 \mathrm{~g}, 4.14 \mathrm{mmol}, 1$ equiv) was added. The mixture was stirred $15 \mathrm{~min}$ and turned to pale yellow and was then allowed to reach the RT and kept for $1 \mathrm{~h}$. The crude product was filtered off through a Celite ${ }^{\circledR}$ pad and rinsed with THF. After evaporation of THF, the crude was purified via chromatography on silica gel column (petroleum ether/ $\mathrm{CH}_{2} \mathrm{Cl}_{2}, 9 / 1$ as eluent, $\mathrm{Rf}=0.63$ and 0.5 ). $0.97 \mathrm{~g}$ (88\% yield) of $\mathbf{1 b}$ (cis/trans mixture) were obtained as a white powder. ${ }^{1} \mathrm{H}$ NMR $(300 \mathrm{MHz}$, Chloroform- $d)$ : $\delta=$ $7.87-7.77(\mathrm{~m}, 3 \mathrm{H}), 7.77-7.66(\mathrm{~m}, 2 \mathrm{H}), 7.52-7.43(\mathrm{~m}, 1 \mathrm{H}), 7.38(\mathrm{ddd}, J=11.7,7.6,2.1 \mathrm{~Hz}$, 1H), $7.30(\mathrm{dd}, J=8.5,1.7 \mathrm{~Hz}, 1 \mathrm{H}), 7.16(\mathrm{~d}, J=5.7 \mathrm{~Hz}, 1 \mathrm{H}), 7.12-7.03(\mathrm{~m}, 1 \mathrm{H}), 7.02-6.94$ $(\mathrm{m}, 1 \mathrm{H}), 6.80(\mathrm{~d}, J=12.2 \mathrm{~Hz}, 1 \mathrm{H}), 6.57(\mathrm{~d}, J=12.2 \mathrm{~Hz}, 1 \mathrm{H}) .{ }^{19} \mathrm{~F}$ NMR $(283 \mathrm{MHz}$, Chloroformd): $\delta=-137.67(\mathrm{~d}, J=20.7 \mathrm{~Hz}),-137.99(\mathrm{~d}, J=21.2 \mathrm{~Hz}),-138.74(\mathrm{~d}, J=21.3 \mathrm{~Hz}),-139.16(\mathrm{~d}$, $J=21.4 \mathrm{~Hz}) .{ }^{13} \mathrm{C}$ NMR $(76 \mathrm{MHz}$, Chloroform- $d$ ): $\delta=152.41(\mathrm{~d}, J=12.3 \mathrm{~Hz}), 151.94,151.74$ $(\mathrm{d}, J=5.6 \mathrm{~Hz}), 151.54,151.23(\mathrm{~d}, J=12.6 \mathrm{~Hz}), 149.13(\mathrm{~d}, J=12.3 \mathrm{~Hz}), 148.66,148.41,148.24$, 148.02 , 147.85, 134.82, 134.24, 133.78, 133.57, 133.33, 132.82, 131.45, 130.00, 128.60, $128.46,128.21,128.09,127.95,127.84,127.10,126.94,126.70,126.62,126.36,126.31$, 125.38, $122.91(\mathrm{dd}, J=6.1,3.3 \mathrm{~Hz}), 117.77,117.49,117.18(\mathrm{~d}, J=17.2 \mathrm{~Hz}), 114.78$ (d, $J=$ $17.8 \mathrm{~Hz}) . \mathrm{MS}(\mathrm{EI}) \mathrm{m} / \mathrm{z}=266.098$; calculated $=266.09$ 
2-(3,4-dichlorostyryl)naphthalene (1c): In a $50 \mathrm{~mL}$ flask under argon was dissolved 3 (2.0 g, $4.14 \mathrm{mmol}, 1$ equiv) in dry $\mathrm{THF}(25 \mathrm{~mL})$. At $-78{ }^{\circ} \mathrm{C}, n$-BuLi $(2.59 \mathrm{~mL}, 4.14 \mathrm{mmol}, 1.6 \mathrm{M}$ in hexane, 1.05 equiv) was slowly added and the mixture turned from white to red. After 15 min stirring, the mixture reached the RT and was stirred for additional $15 \mathrm{~min}$. The mixture was then cooled down at $-78^{\circ} \mathrm{C}$ and 3,4-dichlorobenzaldehyde $(0.72 \mathrm{~g}, 4.14 \mathrm{mmol}, 1$ equiv) was added. The mixture was stirred $15 \mathrm{~min}$ and turned to pale yellow and was then allowed to reach the RT and kept for $1 \mathrm{~h}$. The crude product was filtered off through a celite ${ }^{\circledR}$ pad and rinsed with THF. After evaporation of the THF, the crude was purified via chromatography on silica gel column (petroleum ether/ $\mathrm{CH}_{2} \mathrm{Cl}_{2}, 9 / 1$ as eluent, $\mathrm{Rf}=0.68$ and 0.58 ). $1.02 \mathrm{~g}$ (82\% yield) of 1c (cis/trans mixture) were obtained as a white powder. ${ }^{1} \mathrm{H}$ NMR (300 MHz, Chloroform- $d$ ): $\delta$ $=7.86-7.62(\mathrm{~m}, 9 \mathrm{H}), 7.50-7.43(\mathrm{~m}, 5 \mathrm{H}), 7.39-7.36(\mathrm{~m}, 2 \mathrm{H}), 7.31 \mathrm{f}-7.28(\mathrm{~m}, 1 \mathrm{H}), 7.23(\mathrm{~d}$, $J=3.2 \mathrm{~Hz}, 1 \mathrm{H}), 7.14(\mathrm{~s}, 1 \mathrm{H}), 7.07(\mathrm{~d}, J=8.3 \mathrm{~Hz}, 1 \mathrm{H}), 6.83(\mathrm{~d}, J=12.2 \mathrm{~Hz}, 1 \mathrm{H}), 6.55(\mathrm{~d}, J=$ $12.2 \mathrm{~Hz}, 1 \mathrm{H}) .{ }^{13} \mathrm{C}$ NMR (76 MHz, Chloroform- $d$ ): $\delta=137.56(\mathrm{~d}, J=17.9 \mathrm{~Hz}), 134.10(\mathrm{~d}, J=$ $9.9 \mathrm{~Hz}), 133.75,133.48$ (d, $J=11.2 \mathrm{~Hz}), 132.94$ (d, $J=9.0 \mathrm{~Hz}), 132.47,132.18,131.29,131.10$, 130.93, 130.79 (d, $J=5.4 \mathrm{~Hz}), 130.28,128.64,128.36(\mathrm{~d}, J=4.1 \mathrm{~Hz}), 128.24,128.09$ (d, $J=$ $5.8 \mathrm{~Hz}), 127.97,127.86(\mathrm{~d}, J=3.7 \mathrm{~Hz}), 127.36,126.64(\mathrm{~d}, J=2.4 \mathrm{~Hz}), 126.55,125.80,123.43$. MS $(\mathrm{EI}) \mathrm{m} / \mathrm{z}=298.0310$; calculated $=298.0316$.

2,3-dibromo-[4]-helicene, (H4Br2) (2a): Stilbene 1a (0.7 g, $1.80 \mathrm{mmol}, 1$ equiv) and iodine $(0.46 \mathrm{~g}, 1.80 \mathrm{mmol}, 1$ equiv) were dissolved in toluene $(750 \mathrm{~mL})$. The solution was degassed and propylene oxide $(6.3 \mathrm{~mL}, 90 \mathrm{mmol}, 50$ equiv) was added. The mixture was irradiated for $4 \mathrm{~h}$ with a Hg lamp $(150 \mathrm{~W})$. The procedure was repeated several times for a total of $4.1 \mathrm{~g}$ of stilbene compound 1a. Afterwards, the united crudes were concentrated and purified via chromatography on silica gel column (petroleum ether as eluent). $3.0 \mathrm{~g}$ (74\% yield) of $\mathbf{2 a}$ were obtained as a yellow oil. NB: The desired product is mixed with the monobrominated derivative (3-bromo-[4]-helicene 4a) (2:1 ratio). ${ }^{1} \mathrm{H}$ NMR (300 MHz, Chloroform- $d$ ): $\delta=9.31(\mathrm{~s}, 1 \mathrm{H})$, $8.90(\mathrm{~d}, J=9.01 \mathrm{~Hz}, 1 \mathrm{H}), 8.21(\mathrm{~s}, 1 \mathrm{H}), 8.02(\mathrm{~d}, 1 \mathrm{H}, J=9.1 \mathrm{~Hz}), 7.90(\mathrm{~d}, 1 \mathrm{H}, J=9.1 \mathrm{~Hz}), 7.80-$ $7.62(\mathrm{~m}, 5 \mathrm{H}) .{ }^{13} \mathrm{C}$ NMR $(76 \mathrm{MHz}$, Chloroform- $d$ ): $\delta=133.6,133.5,133.3,132.5,132.4,131.9$, 131.5, 131.4, 131.3, 130.12, 130.08, 129.99, 129.8, 129.0, 128.8, 128.7, 128.42, 128.39, 128.31, 128.1, 127.31, 127.30, 127.1, 127.0, 126.9, 126.7, 126.62, 126.55, 126.34, 126.27, 126.1, 126.0, 125.9, 125.8, 122.4, 121.7, 120.6. MS (MALDI-TOF) $\mathrm{m} / \mathrm{z}=383.9(\mathrm{M}+)$; calculated $=383.91$ (2a). MS (MALDI-TOF) $\mathrm{m} / \mathrm{z}=306.0\left(\mathrm{M}^{+}\right)$; calculated = $306.00(\mathbf{4 a})$.

2-bromobenzo[c]phenanthrene (4a): A mixture of $(E)$ - and (Z)-1-(p-bromophenyl)-2-(2naphthyl)ethylene ${ }^{[39,40]}(0.6 \mathrm{~g}, 1.94 \mathrm{mmol}, 1$ equiv) and iodine (0.49 g, $1.94 \mathrm{mmol}, 1$ equiv) were dissolved in toluene $(650 \mathrm{~mL})$. The solution was degassed for $15 \mathrm{~min}$, and then propylene 
oxide (6.79 mL, $97 \mathrm{mmol}, 50$ equiv) was added. The mixture thus obtained was irradiated under stirring for $16 \mathrm{~h}$ with a Hg lamp $(150 \mathrm{~W})$. The synthesis was replicated in several batches, for a total amount of $1.72 \mathrm{~g}$ of stilbene compound. After evaporation of toluene, the crude was purified by chromatography over silica gel column (petroleum ether/ $\mathrm{CH}_{2} \mathrm{Cl}_{2}, 9 / 1, \mathrm{Rf}=0.45$ ). $1.26 \mathrm{~g}$ (74\% yield) of $\mathbf{4 a}$ were obtained as a light yellow powder.

The spectral data for this compound match those reported in the literature. ${ }^{[40]}$

2,3-difluoro-[4]-helicene \& 1,2-difluoro-[4]-helicene (2b/2b'): Stilbene $1 \mathbf{b}(0.57 \mathrm{~g}, 2.14$ mmol, 1 equiv) and iodine ( $0.54 \mathrm{~g}, 2.14 \mathrm{mmol}, 1$ equiv) were dissolved in toluene $(650 \mathrm{~mL})$. The solution was degassed for $15 \mathrm{~min}$, and then propylene oxide (6.84 mL, $107 \mathrm{mmol}, 50$ equiv) was added. The mixture thus obtained was irradiated under stirring for $16 \mathrm{~h}$ with a $\mathrm{Hg}$ lamp $(150 \mathrm{~W})$. The synthesis was replicated in two batches, for a total amount of $0.97 \mathrm{~g}$ of stilbene compound 1b. After evaporation of toluene, the crude was purified by chromatography over silica gel column (petroleum ether/ $\mathrm{CH}_{2} \mathrm{Cl}_{2}, 9 / 1, \mathrm{Rf}=0.45$ and 0.47 ). $0.63 \mathrm{~g}$ (65\% yield) of $\mathbf{2 b} / \mathbf{2} \mathbf{b}$ ' were obtained as a white powder. A second purification by chromatography over silica gel column petroleum ether $100 \%$ allowed us to separate $\mathbf{2 b}$ and $\mathbf{2 b}$ '. Slow evaporation of $\mathbf{2 b}$ in $\mathrm{CH}_{2} \mathrm{Cl}_{2}$ afforded crystals suitable for X-ray analysis. 2b: ${ }^{1} \mathrm{H} \mathrm{NMR}$ (300 MHz, Chloroformd): $\delta=8.98(\mathrm{~d}, J=8.0 \mathrm{~Hz}, 1 \mathrm{H}), 8.94-8.86(\mathrm{~m}, 1 \mathrm{H}), 8.03(\mathrm{dd}, J=7.8,1.7 \mathrm{~Hz}, 1 \mathrm{H}), 7.92(\mathrm{~d}, J$ $=8.5 \mathrm{~Hz}, 1 \mathrm{H}), 7.82(\mathrm{~d}, J=2.9 \mathrm{~Hz}, 2 \mathrm{H}), 7.81-7.77(\mathrm{~m}, 1 \mathrm{H}), 7.76-7.69(\mathrm{~m}, 2 \mathrm{H}), 7.69-7.62$ $(\mathrm{m}, 1 \mathrm{H}) .{ }^{19} \mathrm{~F}$ NMR $(283 \mathrm{MHz}$, Chloroform- $d$ ): $\delta=-137.33(\mathrm{~d}, J=22.4 \mathrm{~Hz}),-138.24(\mathrm{~d}, J=21.6$ Hz). ${ }^{13} \mathrm{C}$ NMR (76 MHz, Chloroform- $d$ ): $\delta=150.1(\mathrm{dd}, J=232.9 \mathrm{~Hz}, J=13,8 \mathrm{~Hz}), 149.4$ (dd, $J=251.8 \mathrm{~Hz}, J=14,6 \mathrm{~Hz}) 133.65,131.08,130.81(\mathrm{~d}, J=8.5 \mathrm{~Hz}), 130.09,128.93,128.08$, $127.58,127.25(\mathrm{~d}, J=6.9 \mathrm{~Hz}), 127.20-126.93(\mathrm{~m}), 126.89,126.82,126.40,115.23(\mathrm{~d}, J=$ 19.5 Hz), 114.75 (d, $J=16.0 \mathrm{~Hz}) .2 \mathrm{~b}$ ': ${ }^{1} \mathrm{H}$ NMR (300 MHz, Chloroform- $d$ ): $\delta=8.37-8.25(\mathrm{~m}$, $1 \mathrm{H}), 8.05-7.96(\mathrm{~m}, 2 \mathrm{H}), 7.88-7.73(\mathrm{~m}, 4 \mathrm{H}), 7.70-7.60(\mathrm{~m}, 2 \mathrm{H}), 7.53(\mathrm{td}, J=9.2,7.2 \mathrm{~Hz}$, 1H). ${ }^{19} \mathrm{~F}$ NMR (283 MHz, Chloroform- $d$ ): $\delta=-126.30(\mathrm{~d}, J=19.3 \mathrm{~Hz}),-138.88(\mathrm{~d}, J=19.3$ Hz). ${ }^{13} \mathrm{C}$ NMR $(76 \mathrm{MHz}$, Chloroform- $d$ ): $\delta=148.9(\mathrm{dd}, J=248.4 \mathrm{~Hz}, J=14.8 \mathrm{~Hz}), 146.8(\mathrm{dd}$, $J=256 \mathrm{~Hz}, J=13.7 \mathrm{~Hz}), 132.90,132.25,131.19,130.01,129.40,129.20,127.60,127.03$, 126.80, 126.31, 125.98, 125.42, 124.32, 120.21 (d, $J=9.6 \mathrm{~Hz}), 116.22$ (d, $J=19.9 \mathrm{~Hz})$. MS (EI) $\mathrm{m} / \mathrm{z}=264.0746$; calculated $=264.0751$.

\section{2,3-dichloro-[4]-helicene, 1,2-dichloro-[4]-helicene \& 3-chloro-[4]-helicene (2c/2c'/4c):}

Stilbene 1c (0.6 g, $2.01 \mathrm{mmol}, 1$ equiv) and iodine (0.53 g, $2.11 \mathrm{mmol}, 1.05$ equiv) were dissolved in toluene $(650 \mathrm{~mL})$. The solution was degassed for $15 \mathrm{~min}$, and then propylene oxide (7.02 $\mathrm{mL}, 100 \mathrm{mmol}, 50$ equiv) was added. The mixture thus obtained was irradiated under stirring for $16 \mathrm{~h}$ with a $\mathrm{Hg}$ lamp $(150 \mathrm{~W})$. The synthesis was replicated in two batches, for a 
total amount of $1.03 \mathrm{~g}$ of stilbene compound. After evaporation of toluene, the crude was purified by chromatography over silica gel column (petroleum ether/ $\mathrm{CH}_{2} \mathrm{Cl}_{2}, 9 / 1, \mathrm{Rf}=0.5$ ). $0.63 \mathrm{~g}$ (90\% yield) of $\mathbf{2} \mathbf{c} / \mathbf{2} \mathbf{c}^{\mathbf{9}} / \mathbf{4} \mathbf{c}$ were obtained as a white powder. The separation of these three compounds turned out to be very difficult. ${ }^{1} \mathrm{H}$ NMR (300 MHz, Chloroform- $d$ ): $\delta=8.10$ (s, $1 \mathrm{H}), 8.04(\mathrm{dd}, J=7.9,1.5 \mathrm{~Hz}, 1 \mathrm{H}), 7.94(\mathrm{~d}, J=8.5 \mathrm{~Hz}, 1 \mathrm{H}), 7.87$ (s, 0H), 7.83 (d, $J=5.0 \mathrm{~Hz}$, $1 \mathrm{H}), 7.79(\mathrm{~s}, 1 \mathrm{H}), 7.78-7.76(\mathrm{~m}, 1 \mathrm{H}), 7.75(\mathrm{t}, J=1.5 \mathrm{~Hz}, 1 \mathrm{H}), 7.72(\mathrm{~d}, J=1.6 \mathrm{~Hz}, 0.3 \mathrm{H}), 7.69$ $(\mathrm{d}, J=1.3 \mathrm{~Hz}, 0.3 \mathrm{H}), 7.67$ (s, 0.4H), $7.64(\mathrm{~d}, J=1.2 \mathrm{~Hz}, 0.2 \mathrm{H}) .{ }^{13} \mathrm{C}$ NMR $(76 \mathrm{MHz}$, Chloroformd): $\delta=133.75,132.86,131.51,130.63,130.01,129.57,129.34(\mathrm{~d}, J=5.0 \mathrm{~Hz}), 128.96,128.51$ $(\mathrm{d}, J=5.1 \mathrm{~Hz}), 127.29,127.03,126.76,126.52,126.04$. MS $(\mathrm{EI}+) \mathrm{m} / \mathrm{z}=296.0160$; calculated $=296.0160\left(\mathbf{2 c} / \mathbf{2} \mathbf{c}^{\prime}\right)$. MS $(\mathrm{EI}+) \mathrm{m} / \mathrm{z}=260.0510 ;$ calculated $=262.0544(\mathbf{4 c})$.

(naphthalen-2-ylmethyl)triphenylphosphonium bromide (3): In a $500 \mathrm{~mL}$ flask triphenylphosphine (17.8 g, $67.9 \mathrm{mmol}, 1$ equiv) and 2-bromomethylnapthalene (15 g, 67.9 mmol, 1 equiv) were dissolved in xylene $(340 \mathrm{~mL})$. Then the mixture was stirred at reflux for $3 \mathrm{~h}$. After cooling down to room temperature, the white precipitate was filtered off, rinsed with cold diethyl ether and dried under vacuum. The phosphonium salt $\mathbf{3}$ was obtained as a white powder $31.16 \mathrm{~g}$ (95\% yield). ${ }^{1} \mathrm{H}$ NMR (300 MHz, Chloroform- $d$ ): $\delta=7.82-7.67(\mathrm{~m}, 10 \mathrm{H})$, $7.65-7.50(\mathrm{~m}, 9 \mathrm{H}), 7.40(\mathrm{~d}, J=8.4 \mathrm{~Hz}, 2 \mathrm{H}), 7.17(\mathrm{dt}, J=8.3,1.8 \mathrm{~Hz}, 1 \mathrm{H}), 5.61(\mathrm{~d}, J=14.5$ $\mathrm{Hz}, 2 \mathrm{H}) .{ }^{31} \mathrm{P}$ NMR (122 MHz, Chloroform- $d$ ): $\delta=22.95$ (s). ${ }^{13} \mathrm{C}$ NMR (76 MHz, Chloroformd): $\delta=135.01(\mathrm{~d}, J=3.0 \mathrm{~Hz}), 134.53(\mathrm{~d}, J=9.8 \mathrm{~Hz}), 133.00(\mathrm{~d}, J=3.5 \mathrm{~Hz}), 132.72(\mathrm{~d}, J=2.8$ $\mathrm{Hz}), 131.30$ (d, $J=7.3 \mathrm{~Hz}), 130.19(\mathrm{~d}, J=12.5 \mathrm{~Hz}), 128.70$ (d, $J=4.3 \mathrm{~Hz}), 128.45$ (d, $J=2.7$ Hz), 127.94, 127.62, 126.61, 126.43, 124.58 (d, $J=9.1 \mathrm{~Hz}), 118.51,117.37,31.11$ (d, $J=46.6$ $\mathrm{Hz}) . \mathrm{FAB}+\mathrm{m} / \mathrm{z}(-\mathrm{Br})=403.1612$; calculated $=403.1610$.

The spectral data for this compound match those reported in the literature. ${ }^{[23]}$

2-(4,5-dibromo-2-methylstyryl)naphthalene (5): In a flask under argon atmosphere the phosphonium salt 3 (0.7 g, $1.45 \mathrm{mmol}, 1$ equiv) was dissolved in distilled THF (15 mL) and cooled at $-78{ }^{\circ} \mathrm{C}$. Then, $n$-BuLi $(0.6 \mathrm{~mL}, 1.56 \mathrm{mmol}, 2.6 \mathrm{M}$ in hexane 1.05 equiv) was added giving an orange solution. After 15 minutes at $-78{ }^{\circ} \mathrm{C}$ the solution was left to warm at r.t. until the mixture became red. Then, it was cooled at $-78^{\circ} \mathrm{C}$ and 4,5-dibromo-2-methylbenzaldehyde (0.4 g, 1.45 mmol, 1 equiv), synthesized from a known procedure, ${ }^{[41]}$ was added. After 15 minutes at $-78{ }^{\circ} \mathrm{C}$, it was left to warm at r.t. for $3 \mathrm{~h}$. The mixture was concentrated and purified by chromatography (petroleum ether as eluent) leading to $0.56 \mathrm{~g}$ (90\% yield) of $\mathbf{5}$ (cis/trans mixture) obtained as a white powder. ${ }^{1} \mathrm{H}$ NMR $(300 \mathrm{MHz}$, Chloroform- $d): \delta=c i s /$ trans mixture $3: 1$ : 7.82-7.88 (m, 1.8H), 7.71-7.78 (m, 2.4H), $7.64(\mathrm{~s}, 1 \mathrm{H}$, cis), $7.62(\mathrm{~d}, 1 \mathrm{H}$, cis $), 7.42-7.52$ $(\mathrm{m}, 4.9 \mathrm{H}), 7.28\left(\mathrm{~d}, 0.3 \mathrm{H}, J_{\text {trans }}=16.2 \mathrm{~Hz}\right), 7.16\left(\mathrm{~d}, 0.3 \mathrm{H}, J_{\text {trans }}=16.2 \mathrm{~Hz}\right), 7.15(\mathrm{dd}, 1 \mathrm{H}, J=8.5$, 
$1.5 \mathrm{~Hz}, c i s), 6.84\left(\mathrm{~d}, 1 \mathrm{H}, J_{\text {cis }}=12.2 \mathrm{~Hz}\right), 6.54\left(\mathrm{~d}, 1 \mathrm{H}, J_{\text {cis }}=12.2 \mathrm{~Hz}\right), 2.40\left(\mathrm{~s}, 1 \mathrm{H}, \mathrm{CH}_{3}\right.$ trans $)$, $2.20\left(\mathrm{~s}, 3 \mathrm{H}, \mathrm{CH}_{3}\right.$ cis $)$. MS (MALDI-TOF) $\mathrm{m} / \mathrm{z}=400.10\left(\mathrm{M}^{+}\right.$); calculated $=399.95$.

2-bromo-4-methyl-[4]-helicene (6): Stilbene 5 (0.71 g, $1.77 \mathrm{mmol}, 1$ equiv) and iodine (0.45 g, $1.77 \mathrm{mmol}, 1$ equiv) were dissolved in toluene $(750 \mathrm{~mL})$. The solution was degassed and propylene oxide $(6.2 \mathrm{~mL}, 88.5 \mathrm{mmol}, 50$ equiv) was added. The mixture was irradiated for $4 \mathrm{~h}$. Afterwards, the crude was concentrated and purified by chromatography (petroleum ether $100 \%$ ). The target product 7 was not obtained, instead the 2-bromo-4-methyl-[4]-helicene 6 was identified. ${ }^{1} \mathrm{H}$ NMR $(300 \mathrm{MHz}$, Chloroform- $d$ ): $\delta=9.16(\mathrm{~s}, 1 \mathrm{H}), 9.04(\mathrm{~d}, 1 \mathrm{H}, J=8.5 \mathrm{~Hz})$, 8.07 (dd, $1 \mathrm{H}, J=8.8,0.6 \mathrm{~Hz}), 8.07(\mathrm{dd}, 1 \mathrm{H}, J=7.9,1.5 \mathrm{~Hz}), 7.94(\mathrm{~d}, 1 \mathrm{H}, J=8.5 \mathrm{~Hz}), 7.88$ (d, $1 \mathrm{H}, J=8.8 \mathrm{~Hz}), 7.84(\mathrm{~d}, 1 \mathrm{H}, J=8.6 \mathrm{~Hz}), 7.76(\mathrm{td}, 1 \mathrm{H}, J=1.3 \mathrm{~Hz}), 7.68(\mathrm{td}, 1 \mathrm{H}, J=1.3 \mathrm{~Hz})$, $7.63($ br s, $1 \mathrm{H}), 2.3(\mathrm{~s}, 3 \mathrm{H})$. MS (MALDI-TOF) $\mathrm{m} / \mathrm{z}=320.1\left(\mathrm{M}^{+}\right)$; calculated = 320.02.

\subsection{X-Ray structure determinations}

Details about data collection and solution refinement are given in Table S1. A single crystal of 1a was mounted on glass fibre loop using a viscous hydrocarbon oil to coat the crystal and then transferred directly to cold nitrogen stream for data collection. Data collection was performed at $293 \mathrm{~K}$ on an Agilent Supernova with $\mathrm{CuK} \alpha(\lambda=1.54184 \AA)$. The structure was solved by direct methods with the SIR92 program and refined against all $\mathrm{F}^{2}$ values with the SHELXL-97 program using the WinGX graphical user interface.

All non-H atoms were refined anisotropically. Hydrogen atoms were introduced at calculated positions (riding model), included in structure factor calculations but not refined.

Crystallographic data for the structure have been deposited with the Cambridge Crystallographic Data Centre, deposition numbers CCDC 2099575 (1a). These data can be obtained free of charge from CCDC, 12 Union road, Cambridge CB2 1EZ, UK (e-mail: deposit@ccdc.cam.ac.uk or http://www.ccdc.cam.ac.uk).

\subsection{Computational details}

All calculations have been performed with the Gaussian09 program. ${ }^{[42]}$ For all molecules the gas phase ground state geometries have been optimized, without forcing any symmetry, by the Density Functional Theory method with the hybrid PBE0 functional (with $25 \%$ of exact exchange $)^{[43,44]}$ and the augmented and polarized Pople type basis set $6-311++\mathrm{G}(2 \mathrm{df}, 2 \mathrm{pd})$. We have then verified by a frequency calculation that the stationary point correspond to a global minimum on the potential energy surface. The gas phase excited states energies of the stilbenes have been determined at the same level of theory as the ground states by a linear response Time- 
Dependent DFT method considering the first fifteen singlet to singlet excitations. Molecular orbitals (MO), density difference plots (between ground and excited state) pictures have been generated by quchemreport, a homemade automated quality control and report generation python program based on cclib. ${ }^{[45,46]}$ The calculated bar spectra have been enlarged with a gaussian shape $\left(\mathrm{FWHM}=3000 \mathrm{~cm}^{-1}\right)$ with quchemreport to compare with the experiment.

\section{Conflicts of interest}

There are no conflicts to declare.

\section{Acknowledgements}

This work was supported in France by the CNRS, the University of Angers and the RFI LUMOMAT.

\section{Notes and references}

[1] K. B. Jørgensen, Molecules 2010, 15, 4334-4358.

[2] F. B. Mallory, C. S. Wood, J. T. Gordon, J. Am. Chem. Soc. 1964, 86, 3094-3102.

[3] F. B. Mallory, C. S. Wood, J. Org. Chem. 1964, 29, 3374-3377.

[4] F. B. Mallory, C. W. Mallory, Org. React. 1984, 30.

[5] L. Liu, B. Yang, T. J. Katz, J. Org. Chem. 1991, 56, 3769-3775.

[6] R. H. Martin, M. Flammang-Barbieux, J. P. Cosyn, M. Gelbcke, Tetrahedron Lett. 1968, $31,3507-3510$.

[7] R. H. Martin, Angew. Chem. Int. Ed. Engl. 1974, 13, 649-660.

[8] Y. Shen, C.-F. Chen, Chem. Rev. 2012, 112, 1463-1535.

[9] M. Gingras, Chem. Soc. Rev. 2013, 42, 968-1006.

[10] S. Grimme, J. Harren, A. Sobanski, F. Vogtle, Eur. J. Org. Chem. 1998, 8, 1491-1509.

[11] J. Autschbach, Chirality 2010, 22, E116-E152.

[12] M. Gingras, Chem. Soc. Rev. 2013, 42, 1051-1095.

[13] K. Dhbaibi, L. Favereau, J. Crassous, Chem. Rev. 2019, 119, 8846-8953.

[14] F. Pop, N. Zigon, N. Avarvari, Chem. Rev. 2019, 119, 8435-8478.

[15] F. B. Mallory, C. W. Mallory, J. Am. Chem. Soc. 1972, 94, 6041-6048. 
[16] H. Kretzschmann, K. Müller, H. Kolshorn, D. Schollmeyer, H. Meier, Chem. Ber. 1994, $127,1735-1745$.

[17] C. Schnorpfeil, M. Fetten, H. Meier, J. Prakt. Chem. 2000, 342, 785-790.

[18] H. Fukumoto, M. Ando, T. Shiota, H. Izumiya, T. Kubota, Macromolecules 2017, 50, $865-871$.

[19] T. Kogiso, K. Yamamoto, H. Suemune, K. Usui, Org. Biomol. Chem. 2012, 10, 29342936.

[20] C. Wäckerlin, J. Li, A. Mairena, K. Martin, N. Avarvari, K.-H. Ernst, Chem. Commun. 2016, 52, 12694-12697.

[21] J. Li, K. Martin, N. Avarvari, C. Wäckerlin, K.-H. Ernst, Chem. Commun. 2018, 54, 7948-7951.

[22] A. Abhervé, K. Martin, A. Hauser, N. Avarvari, Eur. J. Inorg. Chem. 2019, 4807-4814.

[23] T. Biet, A. Fihey, T. Cauchy, N. Vanthuyne, C. Roussel, J. Crassous, N. Avarvari, Chem. Eur. J. 2013, 19, 13160-13167.

[24] N. Avarvari, J. D. Wallis, J. Mater. Chem. 2009, 19, 4061-4076.

[25] C. Matsuda, Y. Suzuki, H. Katagiri, T. Murase, Chem. Asian J. 2021, 16, 538-547.

[26] H. R. Talele, M. J. Gohil, A. V. Bedekar, Bull. Chem. Soc. Jpn. 2009, 82, 1182-1186.

[27] R. S. Davidson, J. W. Goodin, G. Kemp, Adv. Phys. Org. Chem. 1984, 20, 191-233.

[28] S. Abbate, C. Bazzini, T. Caronna, F. Fontana, C. Gambarotti, F. Gangemi, G. Longhi, A. Mele, I. N. Sora, W. Panzeri, Tetrahedron 2006, 62, 139-148.

[29] J. Bao, P. M. Weber, J. Am. Chem. Soc. 2011, 133, 4164-4167.

[30] I. N. Ioffe, A. A. Granovsky, J. Chem. Theory Comput. 2013, 9, 4973-4990.

[31] Y. Harabuchi, K. Keipert, F. Zahariev, T. Taketsugu, M. S. Gordon, J. Phys. Chem. A 2014, 118, 11987-11998.

[32] R. B. Woodward, R. Hoffmann, J. Am. Chem. Soc. 1965, 87, 395-397.

[33] R. Hoffmann, R. B. Woodward, Acc. Chem. Res. 1968, 1, 17-22.

[34] J. Febvay, C. S. Demmer, P. Retailleau, J. Crassous, L. Abella, J. Autschbach, A. Voituriez, A. Marinetti, Chem. Eur. J. 2019, 25, 15609-15614.

[35] I. N. Ioffe, A. A. Granovsky, J. Chem. Theory Comput. 2013, 9, 4973-4990.

[36] A. G. Lvov, V. Z. Shirinian, A. V. Zakharov, M. M. Krayushkin, V. V. Kachala, I. V. Zavarzin, J. Org. Chem. 2015, 80, 11491-11500.

[37] B. Rajakumar, E. Arunan, Phys. Chem. Chem. Phys. 2003, 5, 3897-3904.

[38] J. R. Duncan, S. A. Solaka, D. W. Setser, B. E. Holmes, J. Phys. Chem. A 2010, 114, 794-803. 
[39] R. H. Martin, J. Moriau, N. Defay, Tetrahedron 1974, 30, 179-185.

[40] M. A. Brooks, L. T. Scott, J. Am. Chem. Soc. 1999, 121, 5444-5449.

[41] M. Kimura, T. Hamakawa, K. Hanabusa, H. Shirai, N. Kobayashi, Inorg. Chem. 2001, $40,4775-4779$.

[42] M. J. Frisch et al., Gaussian 09, Revision D.01, Gaussian, Inc., Wallingford CT, 2016.

[43] J. P. Perdew, K. Burke, M. Ernzerhof, Phys. Rev. Lett. 1996, 77, 3865-3868.

[44] C. Adamo, V. Barone, J. Chem. Phys. 1999, 110, 6158-6170.

[45] T. Cauchy, B. Da Mota, quchemreport. A python program for control quality and automatic generation of quantum chemistry results, University of Angers, 2020.

[46] N. M. O’boyle, A. L. Tenderholt, K. M. Langner, J. Comput. Chem. 2008, 29, 839-845. 